\title{
Colonialidade e decolonialidade na crítica ao racismo e às violações: para refletir sobre os desafios educação em direitos humanos
}

\section{Coloniality and decoloniality in the critique of racism and violations: to reflect on the challenges in human rights education}

\author{
Jucimeri Isolda Silveira* \\ Sergio Luiz Nascimento* \\ Simões Zalembessa**
}

\begin{abstract}
RESUMO
Este artigo parte da reflexão dos efeitos da colonialidade na reprodução da desigualdade e das violências num contexto de ruptura do pacto social e de ameaça à democracia no Brasil. A partir de uma concepção crítica e decolonial em direitos humanos, busca-se relacionar o aprofundamento da desigualdade social, étnico-racial e de gênero, com a colonialidade que age nas instâncias do ser, do saber e do poder e, nessa lógica, conduz as estruturas e sistemas de poder. Por meio de uma pesquisa teórica sobre colonialidade, decolonialidade e desigualdade, são indicados desafios centrais que reposicionam o papel histórico da sociedade civil, das formas de resistência, das lutas sociais, na materialização dos direitos humanos, na direção emancipatória.
\end{abstract}

Palavras-chave: Colonialidade. Decolonialidade. Racismo. Direitos Humanos.

* Pontifícia Universidade Católica do Paraná. Curitiba, Paraná, Brasil. E-mail: jucimeri. silveira@pucpr.br - https://orcid.org/0000-0001-8274-9231. E-mail: axesergio@yahoo.com.br http://orcid 0000-0002-0570-4379

*** Universidade Católica de Moçambique. Beira, Moçambique. E-mail:zalembessa@gmail.com - https://orcid.org/0000-0001-6263-6571 


\begin{abstract}
This article starts with the reflection of the effects of coloniality in the reproduction of inequality and violence in a context of rupture of the social pact and threat to democracy in Brazil. From a critical and decolonial conception of human rights, we seek to relate the deepening of social, ethnicracial and gender inequality with the coloniality that acts in the instances of being, knowledge and power and, in this logic, leads power structures and systems. Through theoretical research on coloniality, decoloniality and inequality, central challenges are indicated that reposition the historical role of civil society, forms of resistance, social struggles, in the materialization of human rights, in the emancipatory direction.
\end{abstract}

Keywords: Coloniality. Decoloniality. Racism. Human rights.

\title{
Introdução
}

Os efeitos do processo colonizador são atualizados nas formas de reprodução da desigualdade histórica, particularmente social, étnico-racial e de gênero, num contexto de modernização conservadora, cuja base é colonial, com consequente acirramento do racismo de Estado em relação aos povos e grupos estigmatizados e oprimidos. Entendemos, nesse sentido, que as relações de dominação e de dependência entre centro e periferia não se restringem a fatores econômicos e políticos, uma vez que abrangem a construção dos conhecimentos, a cultura, a produção de subjetividades políticas, a desigualdade e as violências.

Partimos da compreensão que o cotidiano engendra modos de ser e de pensar, com efeitos de repetição de verdades que se desdobram em preconceito, silenciamento e discriminação. Realidade que condiciona a ocultação das expressões de desigualdade, a opressão dos povos originários e de pessoas e populações consideradas "fora" do padrão hegemônico.

Este artigo aborda os impactos da colonialidade e da decolonialidade, considerando que esta última indica transcender a colonialidade, tendo em vista escolhas teóricas, políticas e epistemológicas de superação das ações econômicas, política e, também, simbólica de ratificação das relações de exploração imposta pelo colonialismo e reproduzidas pela colonialidade e que, atuando sobre gênero e trabalho, conceberam os conceitos de raça e racismo como princípios organizadores do mundo. 
A decolonialidade indica uma postura, uma atitude continua de transformação, transgressões e insurreições que viabilizem a exteriorização do colonialismo/colonialidade não desfazendo-os ou revertendo-os num póscolonialismo, mas sim superando-os. Para tal análise e revisão teórica, são utilizados referentes a partir das contribuições, especialmente, de Quijano (2007), Mignolo (2005), Walsh (2007) e Grosfoguel (2006), que realizam uma elaboração teórica de interpretação e reinterpretação no campo das epistemologias decoloniais, como alternativas à modernidade eurocêntrica afirmada como projeto de civilização. Para uma aproximação com realidade concreta, abordamos a desigualdade e as violências como constitutivas do processo colonizador e do aprofundamento do neoliberalismo.

O cenário de ampliação da agenda neoliberal, especialmente pelas contrarreformas que destroem as conquistas parciais em direitos e os sistemas públicos estatais, revela uma dinâmica de hegemonia de um projeto reacionário que dissemina ódio, racismo e indiferença, e de ampliação das faces perversas de um Estado socialmente penal e economicamente gerencial. Tal realidade, analisada a partir de uma perspectiva crítica dos direitos humanos, tem, contraditoriamente, engendrado possibilidades de fortalecimento das lutas sociais democráticas e emancipatórias, o que supõe, em parte, o reposionamento de instituições democráticas e a formação de frentes e redes de resistência.

\section{Conservadorismo e colonialidade no Estado de exceção}

A formação de um "estado de emergência permanente (ainda que, eventualmente, não declarado no sentido técnico) tornou-se uma das práticas essenciais dos Estados contemporâneos, inclusive dos chamados democráticos", como afirma Agamben (2004, p. 13). O que observamos é a recorrência da adoção de formas institucionais de ataque e eliminação de inimigos políticos ou pessoas e coletivos considerados fora do padrão hegemônico. Tal compreensão possibilita a análise da dinâmica social e institucional de reprodução das inúmeras formas de violência que impactam nas vidas inferiorizadas socialmente.

Num processo de transição, que durou cerca de um século, os teóricos que se debruçaram sobre os estudos das relações raciais entre negros e brancos no Brasil depararam-se com o mito que consistia, segundo Guimarães (1999, p. 13), em "tomar o que eram desigualdades raciais - próprias da ordem racial escravocrata - como desigualdades de classe da ordem competitiva - próprias do capitalismo industrial". Isso porquê, ao lidar com o campo socialmente 
estruturado, percebemos que em todas as instâncias - sejam elas sociais, políticas, econômicas, éticas - lidamos com a interpretação e a reinterpretação das formas de acomodação do racismo no Brasil e, nesse sentido, a sociedade brasileira acomodou-se às mudanças sem alterar as estruturas raciais. Dessa maneira, longe de as desigualdades no Brasil serem apenas uma questão de classe social, como sustentam alguns teóricos, elas passam, também, por questões raciais, de gênero, religiosas, entre outras. O que se configura, particularmente no caso brasileiro, é uma realidade de racismo praticado pelo Estado penal. Entretanto, tal racismo possui vínculos com o processo colonizador e vem sendo aperfeiçoado pelo conservadorismo hegemonizado no Estado e na sociedade, o que o coloca como central nas análises sobre desigualdade e violências.

A ideologização de uma racionalidade dominante, que inclusive justifique e naturalize as opressões, tem sua gênese na colonização, na afirmação de verdades eurocêntricas engendradas na construção de um projeto de modernidade imposto para todas as sociedades exploradas. Assim, as hierarquias sociais que polarizam primitivo/civilizado, oriente/ocidente, moderno/colonial, branco/ negro, rico/pobre, centros/periferias, entre outras classificações, estão presentes nas narrativas reproduzidas socialmente, e muitas vezes incorporadas pelos povos oprimidos e pessoas discriminadas ou criminalizadas.

Ideologicamente, a antropologia física (ou biológica) e a etnologia no século XIX constituíram as ciências auxiliares e ajudaram a esconder os objetivos socioeconômicos das corporações imperialistas e colonialistas (MUNANGA, 2009; FOÉ, 2013). Importante salientar que a desumanização dos colonizados não se limitou apenas ao racismo epistemológico. Na argumentação de Grosfoguel (2006), que analisa o racismo epistêmico, as produções de conhecimento pelos privilegiados pensadores europeus são pautadas no etnocentrismo e no eurocentrismo e sustentam uma lógica que invadiu todos os campos imaginários da formação humana e estabeleceu a exclusividade da verdade sobre as diferentes formas simbólicas que as sociedades representam como legítimas. Tais formas simbólicas estabelecidas como verdades se mostram arraigadas à filosofia, à ciência, inclusive à religião. Importante salientar o legado epistemológico que transcenderá as expressões explícitas e implícitas de racismo. Há um conjunto de indivíduos que concebem como valorização a branquidade e todas as subsequentes formas de dominação social, econômica e cultural vindas desse modelo. Nesse sentido, independentemente da origem étnica do indivíduo, o que conta é a sua assimilação ideológica e epistemológica. O que se vê nos não-europeus (Outros) é o Ser inferior, a desvalorização.

A colonialidade resultou desse constructo de ações no campo econômico, político, sociocultural e, também, simbólicas de ratificação das relações de exploração que se impõem para além da destruição histórica do colonialismo e 
que, atuando sobre gênero e trabalho, concebe os conceitos de raça e do racismo como princípios de organização do mundo, uma vez que se legitima a partir da concepção da superioridade da raça branca. A colonialidade, o eurocentrismo e o capitalismo são elementos constitutivos e específicos do padrão mundial de poder hegemônico, elementos esses afetam a "vida cotidiana da totalidade da população mundial" (QUIJANO, 2005, p. 123). Se funda na imposição de uma classificação racial/étnica da população do mundo como pedra angular do dito padrão de poder e opera em cada um dos planos, âmbitos e dimensões materiais e subjetivas, da existência social cotidiana e da escala social. Originase e mundializa-se a partir da América (QUIJANO, 2000, p. 342).

Neste sentido, a colonialidade deixou como resultado aos dias atuais, ideias de diferenciação e hierarquização social e uma universalização de verdades sustentadas pela hegemonia eurocêntrica que tem suas bases na emergência de uma razão científica, aliada a um projeto de poder e de exploração de povos ideologicamente subalternizados. O chamado modelo civilizatório a ser aplicado em contextos considerados subdesenvolvidos sustenta-se numa concepção etnocêntrica que invisibiliza modos de ser e de pensar (SILVEIRA et al., 2016). A colonialidade, desse modo, atua nas instâncias do ser, do saber e do poder e, nessa lógica, conduz os modelos estruturadores que mantém instituições tradicionais como legitimadoras do discurso que busca se impor como único; que buscam na ideia de convivência e da integração racial e social reduzir as diferenças e as desigualdades a meros acontecimentos histórico-sociais naturalizados. Da estruturação social com base no critério "raça" provém a hierarquização das relações entre dominador e dominado e a consequente naturalização do discurso de superioridade frente às culturas não europeias, vistas como atrasadas ou primitivas. Ademais, a classificação racial, associada ao controle do trabalho, redundou numa "sistemática divisão racial do trabalho" (QUIJANO, 2005, p. 119), pela qual índios, negros e mestiços eram submetidos a formas de controle do trabalho não remuneradas (escravidão, servidão, reciprocidade etc.), enquanto aos brancos era reservado o controle administrativo das colônias e, portanto, o trabalho pago, assalariado. Tal articulação foi imprescindível ao desenvolvimento do capitalismo e à alocação da Europa e da branquitude europeia em seu centro. Assim, esta conformação constituiu um padrão de poder, que segundo Quijano (2007) se funda e se estrutura em dois pilares distintos: o da racialização (forma de classificar a sociedade baseada na ideia de raça); e o da racionalização (formas de classificar o saber).

A ideia de raça foi assumida pelos colonizadores como o principal elemento constitutivo e fundacional das relações de dominação que a conquista colonial exigia. Através de sua invenção, foi possível a racionalização das relações entre os colonizadores e colonizados em identidades históricas que naturalizaram a 
dominação, associada a hierarquias, lugares e papéis sociais correspondentes. Os processos relacionados à meritocracia e à chamada democracia racial brasileira forjaram e forjam esses pilares estruturais numa lógica da ocultação e de dissimulação que se "baseia na ideia de uma sociedade e não no que acontece nessa sociedade" (MASINI, 2000, p. 64). O que percebemos é a afirmação da máxima da inexistência de racismo; de harmonia social a ser cultivada e mantida pelos esforços individuais, de modo a reduzir desvantagens socioeconômicas por meio do mérito.

Essa parte de nossa reflexão ajudou na discussão teórica sobre a colonialidade e como o eurocentrismo fundou na modernidade a ideia-imagem da história única e projetou a civilização humana como uma trajetória que parte de um estado de natureza e culmina na Europa (QUIJANO, 2005, p. 122). Ao discutirmos sobre a ideologização de uma racionalidade dominante, temos que estar cientes dos impactos atuais em determinados grupos subalternizados.

A parte sequente de nossa reflexão irá ajudar na discussão teórica sobre as distinções raciais, de gênero e de classe, bem como sobre a organização do pensamento sócio-histórico-racial brasileiro. Por exemplo, a transição da Monarquia brasileira para a República teve como ponto crucial para a elite de intelectuais brasileiros, formada por médicos, cientistas, cientistas sociais e educadores, um discurso convergente de transformar o Estado brasileiro numa nação em que a ciência, o mérito e a modernidade pautassem todas as relações sociais e raciais a partir do modelo eurocêntrico.

\section{Modernidade, darwinismo social e a lógica meritocrática}

O indivíduo, descaracterizado quanto às relações de classe, é um preceito da meritocracia, conformando, na diferenciação social: oportunidades; vocação; dedicação; e aptidão. O merecimento acaba sendo, na constituição da sociabilidade moderna, o recurso individual pelo poder e distinção social. É com base no princípio da meritocracia que as políticas sociais se estruturam e que o Estado burocrático regula acessos e permanências no contexto social. Servidores são selecionados pela capacidade; estudantes são avaliados pelo merecimento, sob a retórica da competência; trabalhadores são docilizados pela lógica da produtividade, da competição. Dissemina-se a ideologia desenvolvimentista cuja base está na diferenciação social, na ordem e no controle das partes que compõem esta sociedade idealizada. 
$\mathrm{Na}$ modernidade, a meritocracia engendra relações sociais, o que se aprofunda na cultura da competição estimulada socialmente nos processos educativos e na difusão de valores. Daí sua relação com a concepção darwinista da sociedade, assumindo, assim, uma conotação ideológica.

A lógica da distinção pela agregação de poder obtida por vocação, talento e oportunidades está sustentada por um conjunto de valores que localizam os indivíduos em suas posições sociais e econômicas pela capacidade comprovada socialmente. Desse modo, as sociedades modernas se influenciam pelo modo meritocrático de reprodução social. A meritocracia acaba sendo um elemento funcional à sociabilidade capitalista, particularmente na justificação da desigualdade e na valorização da diferença, com impactos nas respostas institucionais do Estado, o que se atualiza e se aprofunda no contexto de afirmação da ideologia neoliberal, de capitalismo financeirizado acompanhado por profunda precarização das condições de vida e trabalho, de redução de direitos.

Uma das referências teóricas e políticas do pensamento conservador é Joseph de Maistre (1753-1821), que recupera os fundamentos políticos identificados em Hobbes (1588-1679), pela defesa aberta do poder absoluto do governante e sua relação com a vontade divina, na aplicação racional desta soberania em nome do povo, supervalorizando a hierarquia e a ordem garantidas pelo Estado, o que será explicitado em outras manifestações ideológicas e políticas, particularmente na denominada Física Social de Auguste Comte (1798-1857), base do pensamento sociológico.

Edmund Burke (1729-1797), em "Reflexões sobre a Revolução na França" (1790), contrapondo-se ao movimento revolucionário, inicia o que poderia ser chamado de "conservadorismo liberal", tendo em vista seu conteúdo reformista, sem ruptura radical com o passado (NETTO, 2011). Sua obra provém do romantismo conservador, hostil à filosofia das luzes, mas com vinculação às defesas políticas conciliatórias com colônias americanas revoltosas e por princípios do Parlamento contra o absolutismo real de Georges II (LÖWY; SAYRE, 1993). Assim, sob os auspícios da ordem, da hierarquia e da tradição, a ideologia conservadora fundamenta a intolerância e justifica o poder dominante legitimado por instituições pautadas nas formas tradicionais de manter a hegemonia de classe e de regular a sociedade (BARROCO, 2008).

Nesse contexto cultural de afirmação da dominação conservadora, Auguste Comte (1798-1857) é identificado como mais um expoente, pelo projeto de instauração de uma sociedade evoluída, com a presença central dos intelectuais. A filosofia positivista deu margem à supremacia da cientificidade, pelo poder absoluto da razão, na sua aproximação com as ciências da natureza. Compreendendo a sociedade como um organismo constituído de partes integradas e coesas que funcionam harmonicamente, diante da postura metodológica 
rígida na objetividade investigativa, Comte oferece componentes heurísticos absolutamente funcionais à ordem burguesa em formação e desenvolvimento, localizando-se como mais uma expressão conservadora.

Para Löwy (1994) a ideologização do positivismo expressa uma reação às ideias negativas, críticas, anárquicas e subversivas da filosofia iluminista e do socialismo utópico. O esquema axiológico e conceitual inaugurado por Auguste Comte e consolidado por Durkheim trarão consequências diretas na formação da cultura e na justificação da ordem, sobretudo pela tese da estabilidade e harmonia entre as partes que compõem a ordem, a justificativa de correções às anormalidades que dificultam o processo evolutivo.

Importante ressaltar que na ideologia conservadora a autoridade é a base essencial da reprodução de instituições do passado: família; Igreja; e corporações. Nessa cadeia de poderes entre indivíduos e família, paróquias e Igreja, Estado e Deus, plasmam-se justificativas teóricas e políticas, visando seu desenvolvimento coeso, presente em intervenções comunitárias, o que possui relação sincrética com componentes de ideologias desenvolvimentistas no contexto da consolidação do capitalismo pós-Segunda Guerra Mundial (SILVEIRA, 2019).

Considerando a reificação das relações sociais sob a ideologia burguesa, as propostas conservadoras são funcionais à reprodução de valores e comportamentos no cotidiano das relações, pela assimilação e reprodução das tradições e do preconceito, de modo a reiterar a realidade desigual, e por isso tal resgate é necessário do ponto de vista teórico e histórico. Nesse contexto é importante salientar o papel que Quijano (2005) descreve sobre a homogeneização da população de um Estado-nação moderno que consiste no controle da geração e da gestão das instituições de autoridade pública e dos mecanismos de violências projetadas na dependência histórico-estrutural.

O pensamento decolonial, na abordagem sobre a colonialidade a partir da crítica ao chamado mito da modernidade, especialmente pelas contribuições do peruano Aníbal Quijano (1930-2018), reconhece os nexos entre o processo de colonização da América Latina e o desenvolvimento do poder econômico e político europeu, sustentado, especialmente, por uma epistemologia dominante, conservadora e com efeitos opressores. O que se identifica no processo colonizador é a imposição do domínio dos corpos pelo patriarcado, pelo machismo, pela imposição de um modelo e uma lógica de exploração do trabalho e da natureza. Trata-se de uma domesticação, de uma colonização do modo de ser da população indígena e escravizada.

Neste sentido, a decolonialidade epistêmica, significa, entre outras coisas, aprender a desaprender (MIGNOLO, 2005). Desaprender a universalidade do conhecimento científico da cultura europeia, do desenvolvimento 
linear e unidirecional da humanidade. Reaprender o papel epistêmico dos conhecimentos subalternos e ancestrais, que são subjugados juntamente com a população constituída por indígenas, negros, quilombolas, mulheres, idosos, crianças, pessoas LGBTI+, ou seja, por identidades que não fazem parte da colonização das identidades.

Ressaltamos que a existência de um mundo moderno-colonial representa uma barreira para a compreensão do mundo a partir do vivido e das epistemes que lhes são constitutivas. A colonialidade do saber é produzida a partir de uma epistemologia hegemônica que interfere nos regimes de pensamento. Por sua vez, a colonialidade do ser se refere à experiência vivida de colonização e seus impactos na linguagem e na visão de mundo dos povos colonizados e explorados historicamente. Assim, a modernidade é elucidada como um processo intrinsecamente vinculado à experiência colonial. Essa distinção entre colonialidade e colonialismo permite explicar a continuidade das formas coloniais de dominação e suas consequências, mesmo após o fim das administrações coloniais, além de demonstrar que essas estruturas de poder passaram a ser reproduzidas pelos mecanismos do sistema-mundo capitalista colonial-moderno. Desse modo, a noção de colonialidade relaciona o processo de colonização das Américas à constituição da economia-mundo capitalista, a partir do século XVI.

A modernidade é capturada como uma visão universal e idealizada da história, associada à defesa do progresso, da ordem, do desenvolvimento. É compreendida como forma de sociedade única, a partir de um padrão hegemônico que associa capitalismo e liberalismo. Por consequência, o projeto de modernidade naturaliza as múltiplas separações e fragmentações próprias dessa sociedade desigual.

A partir desta abordagem, é possível concluir que as narrativas classificatórias de cariz conservador, relacionadas às hierarquias sociais, raciais, de gênero e de modos de apropriação dos recursos naturais, estão associadas à constituição de uma divisão internacional do trabalho e dos territórios, marcada por relações desiguais, entre economias do centro e periféricas, processo que se aprofunda na atualidade de hegemonia de um conservadorismo político.

Consideramos que o paradigma colonialidade-modernidade explica as narrativas sustentadas por uma perspectiva desenvolvimentista com efeitos de dominação sobre os países explorados, com valorização de um padrão civilizatório hegemônico. É, portanto, neste contexto histórico-cultural colonizado que se dá a formação de um ambiente intelectual que molda mentalidades opressoras, sustentadas na ideologia da modernidade. Ao mesmo tempo, agentes e peritos do Estado tendem a operar medidas punitivistas que reforçam a face racista do Estado, a serviço de projetos societários conservadores e reacionários. 
Na contradição e na resistência contra hegemônica emergem processos alternativos de produzir conhecimentos, com questionamento do caráter colonial/ eurocêntrico. Tal insurgência tem contribuído para a construção e valorização de saberes sociais sobre o continente, com crítica aos processos opressores e à ideologia da modernidade como modelo civilizatório universal e natural. Compreendemos, nesse sentido, que a classificação social e étnico-racial da população, e a vinculação do trabalho com as formas de controle, conduziram a uma aceitação social do trabalho pago para brancos, e precarizado para pobres, negros e mulheres; da desigualdade de gênero e étnico-racial, o que reforça que a modernidade é profundamente colonial, que a desigualdade possui raiz no processo colonizador.

O pensamento decolonial possibilita, por sua vez, a análise e a crítica das relações de poder, a construção de alternativas a partir dos contextos locais, para superar as armadilhas da colonialidade, que reproduz a desigualdade, especialmente étnico-racial, de gênero e de classe; a apropriação e a exploração/ destruição da natureza e do meio ambiente. Permite, ainda, a análise crítica das consequências do neoliberalismo em tempos de avanço de projetos políticos autoritários, ultraconservadores e reacionários.

\section{Desigualdade e violações: a urgência das formas de resistências e da educação em direitos humanos}

As políticas governamentais operadas a partir de 2016 aprofundam o neoliberalismo, com efeitos reprodutores da desigualdade histórica. Uma das medidas que exemplificam tal tendência, é a Emenda Constitucional no 95/2016 (BRASIL, 2016), que congela os gastos sociais por 20 anos e inviabiliza serviços sociais públicos e o pacto federativo para a implementação de políticas sociais, que materializam direitos sociais conquistados, como educação, saúde, assistência social, trabalho; e políticas transversais para infâncias e juventudes, mulheres, população LGBTI+, povos indígenas, população em situação de rua, migrantes, entre outras populações que demandam políticas de direitos para atenção, proteção e enfrentamento de desigualdades.

O que se verifica é uma tendência de redução drástica de políticas sociais de Estado, de dispositivos protetivos, de políticas de educação em direitos humanos, de reformas e políticas que reduzam desigualdade de gênero, social e étnico-racial, que combatam as violências e as opressões. Realidade que confirma a hegemonia de um Estado socialmente penal, conservador e criminalizador, ao tempo em que é economicamente gerencial para atender aos interesses do mercado. 
De acordo com o “Atlas da Violência de 2017” (CERQUEIRA et al., 2017), de cada 100 pessoas que sofrem homicídio no país, 71 são negras. A juventude é outro fator que chama a atenção, já que corresponde a $47 \%$ do total de óbitos. No recorte etário entre 15 a 19 anos, esse indicador atinge a marca dos 53,8\%.

Evidente que esta realidade está condicionada por uma conjuntura macro societária e pela dinâmica de violência nos territórios, uma vez o que o processo de estigmatização territorial aprofunda a crença de que determinados espaços se constituem em zonas de não direito e cidade fora da norma. Estigmatização que reforça a aplicação de medidas especiais, derrogatórias (WACQUANT, 2015), de modo que a intervenção sistemática do Estado policial amplia a discriminação e o controle repressivo sobre as populações que vivem em territórios profundamente desiguais e excluídas do acesso aos bens, serviços, direitos e riquezas. A Unesco, responsável pela organização do "Índice de Vulnerabilidade Juvenil" (NAÇÕES UNIDAS BRASIL, 2017), destacou que, além da má remuneração e qualidade dos postos de trabalho, as mulheres negras são aquelas mais sujeitas à violência. De acordo com o documento, mulheres negras entre 15 e 29 anos tem 2,2 mais chances de serem assassinadas no Brasil do que uma mulher branca da mesma idade. Numa conjuntura de redução de direitos e de desmonte de políticas de proteção social, tal realidade é agravada.

A desigualdade racial e de gênero se revela profunda no caso brasileiro. Segundo dados da "Pesquisa Nacional por Amostra de Domicílios" (PNAD), realizada pelo IBGE (2018) referente ao período de 1995 a 2015, uma mulher recebe em média $30 \%$ a menos que um homem. Se essa mulher for negra, ela chega a receber $40 \%$ do salário de um homem branco. Outro fator apontado é o da precarização do trabalho, no qual se reconhece uma escalada de qualificação a partir de gênero e raça. De acordo com a PNAD, 39,08\% das mulheres negras ocupadas estão inseridas em relações precárias de trabalho, seguidas pelos homens negros $(31,6 \%)$, mulheres brancas $(26,9 \%)$ e homens brancos $(20,6 \%)$.

As políticas afirmativas implantadas no Brasil nas últimas décadas possibilitaram uma inserção maior de negros e negras no nível superior. Entre 1995 e 2015, a população adulta negra com 12 anos ou mais de estudo passou de 3,3\% para 12\%. Entretanto, o patamar alcançado em 2015 pelos negros era o mesmo patamar atingido por brancos já em 1995. Já a população branca, quando considerado o mesmo tempo de estudo, praticamente dobrou nesses 20 anos, variando de 12,5\% para 25,9\% (IPEA, 2017). Tais políticas estão ameaçadas diante das decisões governamentais em curso e dos efeitos do congelamento do gasto social.

Sendo o racismo estrutural, cultural e institucional, ele é diretamente vinculado às lutas da classe trabalhadora, dos movimentos e forças sociais em direitos humanos. Compreendemos, nesse sentido, que a eliminação da 
discriminação e da desigualdade racial depende de reformas estruturantes que enfrentem, também, as desigualdades de gênero e de classe, de modo a atuar sobre os efeitos da colonialidade. Entretanto, o racismo institucional e a ausência de políticas públicas inviabilizam, cotidianamente, a garantia de direitos e a proteção às pessoas e populações discriminadas.

A conjuntura tem revelado um ambiente favorável para que posturas conservadoras, reacionárias com traços fascistas se intensifiquem, contribuindo diretamente para o agravamento das múltiplas formas de expressão da violência, do racismo, do machismo, da misoginia, da xenofobia, da LGBTfobia, do feminicídio, do extermínio da população jovem e periférica, indígena, do campo, em situação de rua, conformando um ataque sistemático do Estado penal e da sociedade que reproduz o conservadorismo e as ideologias que elegem os inimigos e as vidas passíveis de eliminação.

$\mathrm{O}$ racismo de Estado se opera nos territórios habitados por sujeitos sociais com direitos negados. São territórios que particularizam desigualdades agravadas pelos efeitos da colonialidade, da acumulação da riqueza e poder, com consequente acesso desigual à renda, riqueza e bens produzidos socialmente. A questão social brasileira é, assim, aprofundada por uma desigualdade histórica e por respostas insuficientes do Estado em termos de políticas públicas.

O que percebemos são trajetórias e processos de ruptura e continuidade, tendo em visa a formação social e suas implicações. Reforçamos, entretanto, o continuum do destino da população negra no que se refere à distribuição desigual e não equitativa dos direitos de cidadania. Destacamos a violenta escalada de homicídios e de criminalização da população jovem negra, mesmo diante da vigência do Plano Nacional de Direitos Humanos. A continuidade do racismo pode ser observada, por exemplo, no campo da educação. Ainda que os movimentos sociais negros tenham atuado na esfera pública do Estado, na formulação de políticas públicas educacionais, na perspectiva da valorização da população negra, os livros didáticos e a literatura infanto-juvenil, por exemplo, têm reproduzido a hierarquização entre brancos e negros. Quanto aos estereótipos, as obras literárias brasileiras, tanto para o público adulto quanto para o público infanto-juvenil, ainda relegam os negros à miserabilidade, promiscuidade, marginalidade, ignorância, escravização, sub-representação (ARAUJO, 2010).

Tal realidade confirma a centralidade da questão racial quando tratamos de questão social e de formação brasileira. De outra face, o aprofundamento da questão social no Brasil de hoje, ao mesmo tempo, suscita o necessário fortalecimento do Estado Democrático de Direito, dos órgãos de defesa de direitos, das redes e frentes sociais de defesa da democracia e dos direitos humanos. 


\section{A potência dos direitos humanos nos processos emancipatórios}

Na concepção histórico-crítica, os direitos humanos são compreendidos como construções sociais, políticas, econômicas e culturais, marcadas pelas contradições e condições objetivas na relação entre Estado e sociedade. Nessa perspectiva, as liberdades fundamentais são reconhecidas e valorizadas. No entanto, compreendemos que a sua garantia exige condições institucionais, sociais, econômicas e culturais que possam torná-las realmente efetivas. Assim, a igualdade está vinculada à liberdade, como condição indispensável para a efetivação dos direitos. Igualdade deixa de ser um princípio formal para se transformar em condição histórica de garantias estruturais, políticas, institucionais, culturais, econômicas e sociais. No âmbito das lutas sociais pela dignidade, coloca-se como horizonte a emancipação humana, quando, historicamente, são superadas todas as formas de desigualdade e de opressão, o que inevitavelmente depende de emancipação política, ou seja, das conquistas políticas e institucionais no âmbito dos direitos. Portanto, para além da forma jurídica do direito, é preciso concretizar sistemas de garantia de direitos humanos, observando-se as condições concretas e o engajamento social, bem como as particularidades socio-históricas (SILVEIRA, 2019).

A partir do diálogo sobre as diferentes concepções, é possível reforçar a centralidade da dignidade como sendo um valor central a ser atingido e, portanto, materializado na vida social. Realidade que requer a luta permanente contra toda forma de exploração, dominação, violência, opressão, desigualdade. Assim, compreendemos que direitos humanos são conquistas parciais relativas à emancipação política, visando à travessia para a emancipação humana, processo que é material e histórico.

Uma perspectiva decolonial em direitos humanos recusa a visão juspositivista e evolucionista. Importante observar que as teorias abstratas, liberais, normativistas e universalistas (por desconsiderarem as condições concretas de cada particularidade) em direitos humanos, compreendem o produto objetivado numa lei ou norma similar como sendo o resultado em si, de modo que as prescrições legais passam a se constituir ideologicamente como o próprio direito humano, com consequências que de certo modo acomodam. Desse modo, o direito pode cumprir uma função de harmonização de conflitos e contenção de insurgências, de justificação das assimetrias e relações desiguais em sociedade (ESCRIVÃO FILHO; SOUSA JUNIOR, 2016). Assim, o que está previsto legalmente pode ser visto como algo garantido, contribuindo para a imobilização dos interessados, posto que se propaga a compreensão de que as demandas, reivindicações e necessidades foram satisfeitas. 
Os direitos humanos são dotados de potencial democrático, por serem forjados nas lutas sociais, pela prática dos sujeitos sociais, na explicitação de carecimentos e desigualdades nas democracias. Destacamos, assim, a importância da qualificação legal e institucional de garantias fundamentais, o que inclui a produção de legislações e a institucionalidade de políticas públicas, em resposta às necessidades humanas, e do fortalecimento de organizações e sujeitos coletivos, especialmente com grau maior de conscientização, no processo de democracia formal, indispensável, embora insuficiente. Daí a importância dos movimentos sociais, da visibilidade das formas de resistência, de modo a contribuírem para a construção de uma nova ética em sociedade (SILVEIRA, 2019).

A efetivação dos direitos humanos implica, do ponto de vista de uma matriz da teoria crítica, a combinação "de um processo bastante complexo no qual se intervêm aspectos normativos, políticos, ideológicos, sociais, culturais e econômicos" (CARBALLIDO, 2014, p. 48). Portanto, a materialização de tais direitos, que não se esgotam nos processos de judicialização internacional e nacional, embora estes sejam importantes, supõe desconstruir a cultura de insensibilidade coletiva, da naturalização da desigualdade e de toda forma de opressão e silenciamento.

A compreensão de que os direitos humanos são socialmente construídos e fazem parte das grandes conquistas nos contextos de lutas sociais pela dignidade, como afirma Herrera Flores (2009), contra os arbítrios, os autoritarismos e as arbitrariedades do Estado e das instituições, é base elementar da educação para a cidadania e das formas de resistência e incidência política. Direitos resultam das relações em sociedade nas dimensões, especialmente, da liberdade, igualdade e solidariedade. As lutas sociais, dinamizadas por um conjunto diverso de sujeitos coletivos, notadamente os movimentos sociais e populares, os sindicatos, as organizações da sociedade civil que atuam sobre temas sociais, engendram as conquistas normativo-jurídicas e a produção de novos sentidos e bens simbólicos, além da construção social e política de mecanismos que efetivem os direitos e materializam a dignidade humana.

Uma postura decolonial requer, entre outros aspectos a) o reconhecimento das lutas sociais, das formas de organização que favorecem deslocamentos de poderes e transformações; a centralidade dos sujeitos de direitos e coletivos, na conquista por direitos; b) o reconhecimento da produção de subjetividades como processo aberto de afirmação das diferenças, das singularidades, da autonomia dos sujeitos de direitos; o desocultamento das identidades e modos de pensar e viver; c) a defesa da interdependência entre os direitos de liberdade e os direitos de igualdade, tanto na análise das contradições entre previsões nacionais/internacionais, como na identificação de caminhos para a efetivação dos direitos vocalizados pelos sujeitos; d) a materialidade dos direitos produzidos 
socialmente na esfera pública do Estado, com impactos efetivos nas condições de vida e reversão dos processos de subalternização, desigualdade e violações; a afirmação de uma direção emancipatória na orientação das práxis em sociedade, tendo por horizonte a construção de uma sociabilidade que efetive as liberdades e diversidade, assim como relações igualitárias; produção de conhecimentos que contribuam para a promoção dos direitos humanos, das diversidades, com relevância social e conteúdo ético-político emancipatório (SILVEIRA, 2019).

O que se coloca como horizonte e processo, especialmente no cenário atual, é o fortalecimento de uma cultura dos direitos, com forte atuação de instituições defensoras de direitos e portadoras de futuro efetivamente democrático; a convivência pacífica e solidária em sociedade, com redução das desigualdades e das violações, e intensa disseminação de ações em direitos humanos; o reconhecimento das diferenças e a valorização das diversidades, com ampliação do papel de uma sociedade civil com potencial hegemonia de projetos democráticos e emancipatórios na afirmação de novos projetos societários (SIVEIRA, 2019).

No entanto, tais premissas são abstratas se não forem concretizadas. Os Planos e Programas Nacionais de Direitos Humanos figuraram como recomendações inalcançáveis, caso não sejam transformados em políticas públicas. No mundo terreno, as desigualdades ainda são latentes e alguns índices alarmantes, basta destacar o número assustador de vidas interrompidas por mortes violentas, de pessoas encarceradas. Como discutido ao longo do texto, a superação das expressões de desigualdade depende, dentro outros aspectos, de políticas e ações estratégicas voltadas para os direitos humanos, com ênfase na interculturalidade, na decolonialidade. Tais processos significam a construção de outro conhecimento, outra prática política, outro poder estatal e de outra forma de sociedade. Entretanto, os processos emancipatórios surgem do lugar político de enunciação dos movimentos sociais indígenas, dos movimentos sociais negros, de outros movimentos subalternos, dos movimentos sociais feministas, e, por isso, se diferenciam do multiculturalismo funcional. A visibilização dos conhecimentos outros não deve ser entendida como um resgate de missão fundamentalista ou essencialista pela autenticidade cultural, mas sim como um resgate da diferença colonial no processo de produção do conhecimento, uma vez que não existem conhecimentos neutros, como quer o eurocentrismo, já que todo conhecimento se vincula a lutas específicas e pontos de observação (CASTRO-GÓMEZ, 2007; WALSH, 2007). Ao mesmo tempo, a concretização de direitos humanos orientados pela interculturalidade e decolonialidade requer dispositivos democráticos para além da simples consulta no ato da criação de normas, tratados e recomendações jurídicas. Tais dispositivos devem ser cotidianos, produzidos com participação cidadã nas múltiplas esferas da 
sociedade, desde as organizações educacionais com currículos democráticos até às esferas da segurança pública e do sistema de justiça, na direção e políticas públicas distanciadas das lógicas de etiquetamento social ou de preconceitos e discriminações de seus agentes na vida em sociedade.

A partir de uma visão contemporânea e crítica, os direitos humanos podem ser compreendidos como processos sociais, políticos, econômicos e normativos que possibilitam tanto a abertura quanto a consolidação de espaços de luta pela dignidade humana, orientados por projetos de sociedade (SILVEIRA, 2019). Assim, a crítica aos efeitos do processo colonizador, da modernização conservadora e do avanço do conservadorismo nos marcos de um Estado racista, é parte fundamental de um processo que é coletivo e societário, de retomada das bases fundantes de um Estado Democrático de Direito.

\section{Considerações finais}

A realidade brasileira, latino-americana e Africana é marcada por uma desigualdade estrutural relacionada à formação social colonial, escravocrata e patriarcal, que reproduz e aprofunda as expressões da desigualdade de gênero, de classe, étnico-racial, além dos ciclos de totalitarismos e conflitos, que contribuíram para o enraizamento da cultura de violência, do ódio e do autoritarismo. Por isso, a compreensão crítica de Direitos Humanos demanda uma análise das particularidades das formações sociais, das lutas sociais por direitos, por dignidade.

Em tempos de profundos retrocessos, de ameaça à democracia, especialmente no caso brasileiro; de destruição dos direitos, das políticas sociais, a exemplo da educação pública, com o avanço do neoliberalismo; de contrarreforma; de precarização das condições de vida da classe trabalhadora; de configuração de um Estado penal para a população que vivencia a desigualdade, e gerencial para os interesses do capital, com avanço do conservadorismo, com propagação dos discursos e atos de ódio, ressaltamos o desafio do fortalecimento da resistência, da defesa da cultura e da materialização dos direitos, numa perspectiva decolonial.

Os direitos humanos são indissociáveis da democracia, são afirmados em contextos históricos de enfrentamento dos totalitarismos de Estado. Não são concessões estatais já que são produzidos socialmente e por isso se expressam como conquistas diante de cenários reais de opressão e de desigualdade no acesso aos bens, riquezas, serviços sociais públicos, poder e participação em sociedade. 
O enfrentamento do racismo do Estado e do conjunto de opressões, reposiciona, portanto, a centralidade dos sujeitos de direitos, dos movimentos sociais e outras formas de organização pela sociedade civil, especialmente aquelas que portam projetos de sociedade democrática e emancipada, com educação em direitos humanos e ativismo social, na direção da real superação das estruturas de dominação e de opressão. Compreensão que demanda a afirmação da diversidade humana, com fortalecimento das formas de resistência, na luta social pela dignidade humana, na direção emancipatória.

\section{REFERÊNCIAS}

AGAMBEN, Giorgio. Estado de Exceção. São Paulo: Boitempo, 2004.

BARROCO, Maria Lúcia. Ética: fundamentos sócio-históricos. São Paulo: Cortez, 2008.

BRASIL. Emenda Constitucional $\mathrm{n}^{\circ}$ 95, de 15 de dezembro de 2016. Altera o Ato das Disposições Constitucionais Transitórias, para instituir o Novo Regime Fiscal, e dá outras providências. Diário Oficial da União, Brasília, DF, 15 dez. 2016. Disponível em: http://www.planalto.gov.br/ccivil_03/constituicao/emendas/emc/emc95.htm. Acesso em: 21 set. 2019.

ARAUJO, Cristina Débora. Relações Raciais, Discurso e literatura infanto juvenil. 2010. 192 f. Dissertação (Mestrado em Educação) - Universidade Federal do Paraná, Curitiba, 2010.

CARBALLIDO, Manuel Eugenio Gándara. Repensando los derechos humanos desde las luchas. Revista de Direitos Fundamentais e Democracia, Curitiba, v. 15, n. 15, p. 41-52, 2014. Disponível em: https://revistaeletronicardfd.unibrasil.com.br/index.php/ rdfd/article/view/488. Acesso em: 20 set. 2019.

CASTRO-GÓMEZ, Santiago. Descolonizar la universidad. La hybris del punto cero y el diálogo de saberes. In: CASTRO-GÓMEZ, Santiago; GROSFOGUEL, Ramón (org.). El giro decolonial: reflexiones para una diversidad epistémica más allá del capitalismo global. Bogotá: Siglo del Hombre Editores, 2007. p. 79-91.

CERQUEIRA, Daniel et al. Atlas da Violência 2017. Brasília, DF: IPEA, 2017. Disponível em: https://www.ipea.gov.br/atlasviolencia/publicacoes/47/atlas-da-violencia-2017. Acesso em: 26 out. 2019.

ESCRIVÃO FILHO, Antônio; SOUSA JUNIOR, José Geraldo de. Para um debate teórico-conceitual e político sobre os direitos humanos. Belo Horizonte: D'Placido, 2016. 
FOÉ, Nkolo. África em diálogo, África em autoquestionamento: universalismo ou provincianismo? Acomodação de Atlanta ou iniciativa histórica? Educar em Revista, Curitiba, Brasil, n. 47, p. 175-228, 2013. Disponível em: https://revistas.ufpr.br/educar/ article/view/31332. Acesso em: 20 set. 2019.

GUIMARÃES, Antônio Sérgio Alfredo. As elites de cor os estudos de relações raciais. Tempo Social Rev. Sociol., São Paulo, v. 8, n. 2, p. 67-82, 1996. Disponível em: http:// www.scielo.br/pdf/ts/v8n2/0103-2070-ts-08-02-0067.pdf. Acesso em: 15 nov. 2019.

GROSFOGUEL, Ramón. La descolonización de la economía-política y los estudios poscoloniales: transmodernidad, pensamiento fronterizo y colonialidad global. Tábula Rasa, Bogotá, n. 4, p. 17-48, 2006. Disponível em: http://www.scielo.org.co/pdf/tara/ n4/n4a02.pdf. Acesso em: 15 nov. 2019.

HERRERA FLORES, Joaquín. A (re)invenção dos direitos humanos. Florianópolis: Fundação Boiteux, 2009.

IBGE (INSTITUTO BRASILEIRO DE GEOGRAFIA E ESTATÍSTICA). Pesquisa Nacional por Amostra de Domicílios: síntese de indicadores 2018. Rio de Janeiro: IBGE, 2018.

IPEA (INSTITUTO DE PESQUISA ECONÔMICA APLICADA). Estudo mostra desigualdades de gênero e raça em 20 anos. Brasília, DF: IPEA, 2017. Disponível em: https:// www.ipea.gov.br/portal/index.php?option=com_content\&view=article\&id=29526. Acesso em: 25 out. 2019.

LÖWY, Michael; SAYRE, Robert. Romantismo e política. Rio de Janeiro: Paz e Terra, 1993.

LÖWY, Michael. As aventuras de Karl Marx contra o Barão de Münchhausen: marxismo e positivismo na sociologia do conhecimento. 5. ed. São Paulo: Cortez, 1994.

MASINI, Elsie. Enfoque fenomenológico de pesquisa em educação. 6 ed. São Paulo: Cortez, 2000.

MIGNOLO, Walter. A colonialidade de cabo a rabo: o hemisfério ocidental no horizonte conceitual da modernidade. In: LANDER, Edgardo (org.). A colonialidade do saber: eurocentrismo e ciências sociais. Perspectivas latino-americanas. Buenos Aires: Clacso, 2005. p. 34-54.

MUNANGA, Kabengele. Negritude: usos e sentidos. Belo Horizonte: Autêntica, 2009.

NAÇÕES UNIDAS BRASIL. Violência contra Crianças e Adolescentes: Análise de Cenários e Propostas de Políticas Públicas, 2017. Disponível em: https://nacoesunidas. org/jovem-negra-tem-2-vezes-mais-chance-de-ser-assassinada-no-brasil-revela-unesco/. Acesso em: 25 out. 2019.

NETTO, Leila Escorsim. O conservadorismo clássico: elementos de caracterização crítica. São Paulo: Cortez, 2011. 
QUIJANO, Aníbal. Colonialidad del Poder y Clasificacion Social. Journal of WorldSystems Research, [s.l.], v. 6, n. 2, p. 342-386, 2000.

QUIJANO, Aníbal. Colonialidad del poder, eurocentrismo y América Latina. In: LANDER, Edgardo (org.). La colonialidad del saber: eurocentrismo y ciencias sociales. Perspectivas Latinoamericanas. Buenos Aires: Clacso, 2005. p. 116-142.

QUIJANO, Aníbal. Colonialidad del poder y clasificación social. In: CASTRO-GÓMEZ, Santiago; GROSFOGUEL, Ramon (org.). El giro decolonial: reflexiones para una diversidade epistémica mas allá del capitalismo global. Bogotá: Siglo del Hombre Editores, 2007.

SILVEIRA, Jucimeri Isolda et al. Políticas públicas e direitos humanos: crítica aos fundamentos epistemológicos e a incidência dos sujeitos políticos. In: LIMA, Cezar Bueno de; GUEBERT, Miriam Célia Castellain (org.). Teoria dos direitos humanos em perspectiva interdisciplinar. Curitiba: PUCPRESS, 2016. p. 69-95.

SILVEIRA, Jucimeri Isolda. Direitos humanos e políticas públicas: panorama e desafios. In: BONETI, Lindomar Wessler et al. (org.). Educação em direitos humanos: história, epistemologia e práticas pedagógicas. Ponta Grossa: Editora UEPG, 2019. p. 57-76.

WACQUANT, Loïc. A estigmatização territorial na idade da marginalidade avançada. Sociologia: Revista da Faculdade de Letras da Universidade do Porto, Porto, v. 16, p. 27-39, 2015. Disponível em: http://ojs.letras.up.pt/index.php/Sociologia/article/ view/2365. Acesso em: 25 mar. 2019.

WALSH, Catherine. Introducción. Lo pedagógico y lo decolonial: Entretejiendo caminos. In: WALSH, Catherine (org.). Pedagogías decoloniales: prácticas insurgentes de resistir, (re)existir y (re)vivir Tomo I. Quito: Abya Yala, 2007. p. 585-590. (Serie Pensamiento Decolonial).

Texto recebido em 09/04/2021.

Texto aprovado em 15/06/2021. 